\title{
Kızılırmak Nehrinde Bazı İstasyonlardaki Akımların Trend Analizi
}

\author{
Murat AY ${ }^{1}$ \\ Özgür Kișisi ${ }^{2}$
}

Öz

Bu çalışmada, Şen (2012) ve Şen (2015) tarafından önerilen oldukça yeni bir trend metodu, Kızılırmak havzasından seçilen Şefaatli, Kuyluş, Salur Köprüsü ve Bulakbaşı akım gözlem istasyonlarında aylık olarak ölçülen akım verilerine uygulanmıştır. Aynı verilere MannKendall trend testi de uygulanarak sonuçlar tartışılmıştır. Mann-Kendall testine göre \%95 güven aralığında Kuylus ve Bulakbaşı istasyonlarında trend olmayıp Şefaatli ve Salur Köprüsü istasyonlarında azalan bir trend görülmüştür. Şen trend testine göre ise her bir istasyon için düşük, orta ve yüksek akım değerlerinde farklı trendler gözlenmiştir. Neticede, yeni önerilen Şen metodunda, özellikle görsel olarak veri değerlendirme aşamasında tüm aralıklardaki trendlerin yorumlanabilmesi önemli bir avantaj olarak görülmüsstür.

Anahtar Kelimeler: Akım, Mann-Kendall test, şen trend testi, Türkiye.

\begin{abstract}
Trend Analysis of Streamflows at Some Gauging Stations Over the Kizilirmak River

In this study, a new trend method recently proposed by Şen is used for monthly streamflow data of four different stations, Sefaatli, Kuylus, Salur Bridge and Bulakbasi, selected from the Kizilirmak Basin in Turkey. The Mann-Kendall trend test is also applied to the same data, and the results are discussed. According to the Mann-Kendall test, a significantly decreasing trend is found for the Sefaatli and Salur Bridge stations while there is no trend in the Kuylus and Bulakbasi stations at a significant level of $95 \%$. Different trends are found for the low, medium and high streamflows of each station in view of the Şen trend test. As a result, it can be said that the proposed new method of Şen can identify the trends of low, medium, and high streamflows.
\end{abstract}

Keywords: Streamflow, Mann-Kendall test, şen trend test, Turkey.

Not: Bu yazı

- Yayın Kurulu'na 23.02.2015 günü ulaşmıştır.

- 30 Haziran 2017 gününe kadar tartı̧̧maya açıktır.

1 Bozok Üniversitesi, İnşaat Mühendisliği Bölümü, Yozgat - murat.ay@bozok.edu.tr

2 Canik Başarı Üniversitesi, İnşaat Mühendisliği Bölümü, Samsun - okisi@basari.edu.tr 
Kızllırmak Nehrinde Bazı İstasyonlardaki Akımların Trend Analizi

\section{GíRiş}

Kritik bir parametre olan nehir akımının ölçülmesinin, bir akarsuyun enerji üretim potansiyeli, içme veya sulama suyu kullanımı, bölgedeki taşkın kontrolü ve diğer bir takım amaçlardan dolayı bölgeye yapılan veya yapılacak olan projelerde önemli bir aşama olduğu bilinmektedir. Bu kapsamda, meteorolojik, hidrolojik ve iklimsel olaylardan ötürü değişen veya sabit kalan parametre değerlerinin ne yönde bir trendin olduğunu belirleyebilmek ise ayrıca önemlidir. Yer kürede ve atmosferde meydana gelen değişiklikler meteorolojik olayları ve buna bağlı olarak hidrolojik çevrimi etkilemektedir. Bu etkilerin nitelikleri ve nicelikleri de bölgeden bölgeye değişebilmekte ve etkileri hâlâ araştırılmaktadır. Bu sistemin içerisinde yer alan akım değişkeninin miktarında da değişme ve bazı bölgelerde azalma veya artma olmaktadır. Bu durum, çözülmesi gereken farklı durumlar ortaya çıkarmaktadır. Son yıllardaki çalışmalara bakıldığında konunun teknik boyutlarının yanında sosyal boyutlarının da olduğu görülmektedir [1]. Bu kapsamda, küresel iklim değişikliğinin de etkisiyle, incelenen birçok meteorolojik ve hidrolojik olaylardaki değişkenlerin çözümüne yönelik hem Türkiye'de hem de diğer ülkelerde araştırmalar [2-19] devam etmektedir. Yapılan çalışmalarda en çok üzerinde durulan değişkenlerin sıcaklık, akım ve yağı̧s değişkenleri olduğu görülmektedir. Örneğin, Kadıŏglu (1997) [20], Türkiye'nin değişik yerlerindeki farklı 18 istasyonda 1929 ile 1990 yılları arasında ölçülen sıcaklık değişkeni verilerini kullanmış ve Mann-Kendall (MK) trend metodu ile yerel ve bölgesel trend analizlerini araştırmıştır. Burn ve Elnur (2002) [21], Kanada'da akım değişkeninin yıllık, ortalama, maksimum değerleri gibi 18 hidrolojik ve meteorolojik değişkeni ele alarak MK testi ile bölgede bir trend olup olmadığını araştırmışlardır. Sonuç olarak, Kanada'nın güneyindeki alanlarda yıllık maksimum akımlarda azalıs trendi olduğunu, kuzey bölgelerinde ise bir artış trendi olduğunu belirlemişlerdir. Kahya ve Kalaycı (2004) [22] Yenilebilir Enerji Genel Müdürlüğü tarafından ölçülen ve Türkiye'nin 25 havzasından seçilen toplam 83 (5 istasyon haricinde) istasyona ait 31 yıllık (1964-1994) aylık ortalama akım değişkeni verilerini kullanarak Sen's T, Spearman's Rho, Mann-Kendall ve Mevsimsel Kendall yöntemleri ile trend analizi yapmışlardır. Ayrıca verilerin homojenlik testleri için Van Belle ve Hughe metodunu [23] kullanarak homojen ve homojen olmayan istasyon verilerini tespit etmişlerdir. Birsan vd. (2005) [24] İsviçre'deki 48 havzaya ait ortalama günlük akım ve yağış ile günlük maksimum ve minimum sıcaklık değişkenlerini kullanarak üç farklı veri periyodunda (1931-2000, 1961-2000 ve 1971-2000) trendlerini MK testi ile analiz etmişlerdir. Ayrıca, üç farklı zaman aralığındaki 4 mevsim değişiminin de haritalarını göstermişlerdir. Cı̆̆ızoğlu vd. (2005) [9] Türkiye'de 24 hidrolojik havzada bulunan toplam 100 adet akım gözlem istasyonuna (AGI) ait ortalama, maksimum ve düşük akımlı akımların trend analizlerini araştırmışlardır. Birkaç seri haricinde akım değerlerinin azalan bir trendin olduğunu tespit etmişlerdir. Ayrıca, Türkiye'de yağış değişkeni için yapılan diğer çalışmalarda bulunan trendleri, kendi çalışmaları ile karşılaştırmışlardır. Sonuç olarak, akım trendlerinin, diğer yağış değişkeni trendleri ile paralel olduğunu ifade etmişlerdir. Gocic ve Trajkovic (2013) [25], ylllık ve mevsimsel olarak 7 meteorolojik değişkenin 1980-2010 yılları arasında Sırbistan'daki 12 istasyonun verileriyle MK ve Sen'in eğim (Sen's slope) metodu ile trendleri analiz etmişlerdir.

Bu çalışmada ise Kızılırmak Havzası'ndan seçilen 1517 (Karanlık Dere), 1524 (Gökırmak), 1528 (Salur Köprüsü) ve 1539 (Bulakbaşı) AGI'ye ait aylık akım verileri hem MannKendall hem de yeni önerilen Şen yöntemleri ile analiz edilmiş ve sonuçlar tartışılmıştır. 


\section{2. ÇALIŞMA ALANI VE YÖNTEMLER}

Türkiye'nin Kızılırmak Havzası'nda bulunan 1517 (Karanlık Dere, Şefaatli), 1524 (Gökırmak, Kuyluş), 1528 (Kızılırmak Nehri, Salur Köprüsü) ve 1539 (Kızılırmak Nehri, Bulakbaşı) 4 farklı AGI'de aylık ölçülen akım verileri çalışmada kullanılmıştır. Şekil 1'de istasyonların yerleri gösterilmekte olup diğer özellikleri Çizelge 1'de verilmiş̧ir.
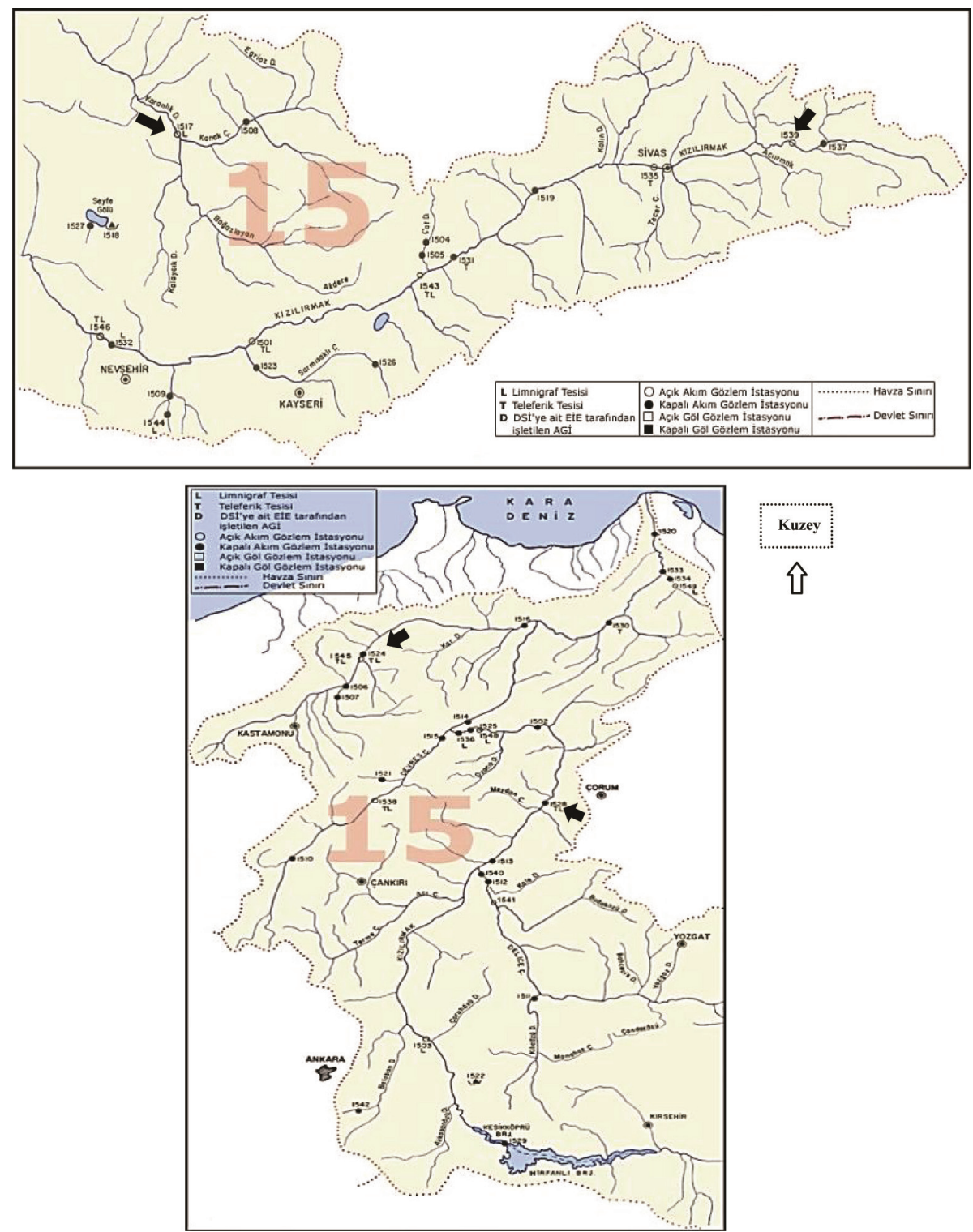

Sekil 1. Türkiye haritası üzerinde istasyonların gösterimi (YEGM) istasyon yerleri) (15 havza numaralı Kızılırmak havzasının güney ve kuzey bölümleri) 
Kızllırmak Nehrinde Bazı İstasyonlardaki Akımların Trend Analizi

Çizelge 1. İncelenen AGI'lerin bazı özellikleri (YEGM, 2000)

\begin{tabular}{|c|c|c|c|c|}
\hline $\begin{array}{c}\text { İstasyon } \\
\text { numarası } \\
\end{array}$ & Koordinatları & $\begin{array}{c}\text { Yükseltisi } \\
\text { (m) }\end{array}$ & $\begin{array}{l}\text { Brüt yağıs } \\
\text { alanı }\left(\mathbf{k m}^{2}\right)\end{array}$ & $\begin{array}{c}\text { Net yağış } \\
\text { alanı }\left(\mathbf{k m}^{2}\right)\end{array}$ \\
\hline 1517 & $34^{\circ} 44^{\prime} 42^{\prime \prime} \mathrm{D}-39^{\circ} 30^{\prime} 11^{\prime \prime} \mathrm{K}$ & 895 & 8592.4 & 5674.4 \\
\hline 1524 & $34^{\circ} 20^{\prime} 12^{\prime \prime} \mathrm{D}-41^{\circ} 35^{\prime} 7^{\prime \prime} \mathrm{K}$ & 475 & 4192.4 & 3914.9 \\
\hline 1528 & $34^{\circ} 39^{\prime} 2^{\prime \prime} \mathrm{D}-40^{\circ} 39^{\prime} 5^{\prime \prime} \mathrm{K}$ & 494 & 57612.4 & 29471 \\
\hline 1539 & $37^{\circ} 33^{\prime} 43^{\prime \prime}$ D-39 $59^{\circ} 36^{\prime \prime} \mathrm{K}$ & 1298 & 1642 & 1642 \\
\hline
\end{tabular}

Hidrolojik çevrimin önemli elemanları olan akım değişkenin zaman serilerindeki trend analizlerinde, parametrik ve parametrik olmayan sayısal analiz yöntemleri kullanılmaktadır. $\mathrm{Bu}$ analiz yöntemlerinden lineer regresyon modeli parametrik bir yöntem olup MK Testi, Spearman's rho (SR) ve Sen's Eğim testleri ise parametrik olmayan yöntemler arasında yer almaktadır. Bu yöntemler literatürde sıklıkla kullanılmakta olup aşă̆ıdaki başlıklarda bu çalışmada kullanılan yöntemler açıklanmıştır.

\section{1. Şen (2012) ve Şen (2015) trend belirleme yöntemi}

$\mathrm{Bu}$ yöntemde, ölçümü alınan hidrolojik değişkenin veri serisi, zamansal olarak ölçüm başlangıç tarihinden son ölçüm tarihine doğru sıralanır. Daha sonra, oluşan seri ilk tarihten itibaren iki eşit parçaya bölünür ve ayrı ayrı kendi içinde küçükten büyüğe doğru sıralanır. Daha sonra, Kartezyen koordinat sistemine göre, oluşan iki veri sütununun ilki $\left(\mathrm{X}_{\mathrm{i}}\right) \mathrm{X}$ eksenine, diğeri $\left(\mathrm{X}_{\mathrm{j}}\right)$ ise $\mathrm{Y}$-eksenine yerleştirilir (Şekil 2). Oluşan iki boyutlu grafik üzerinde veri noktaları $1: 1\left(45^{\circ}\right)$ çizgisinin üzerine toplanmış ise bir trend yoktur ( $a$ trendless time series); altında ise azalan bir trend (a decreasing trend) vardır; üstünde ise artan bir trend (an increasing trend) vardır şeklinde yorumlanmaktadır [14-16].

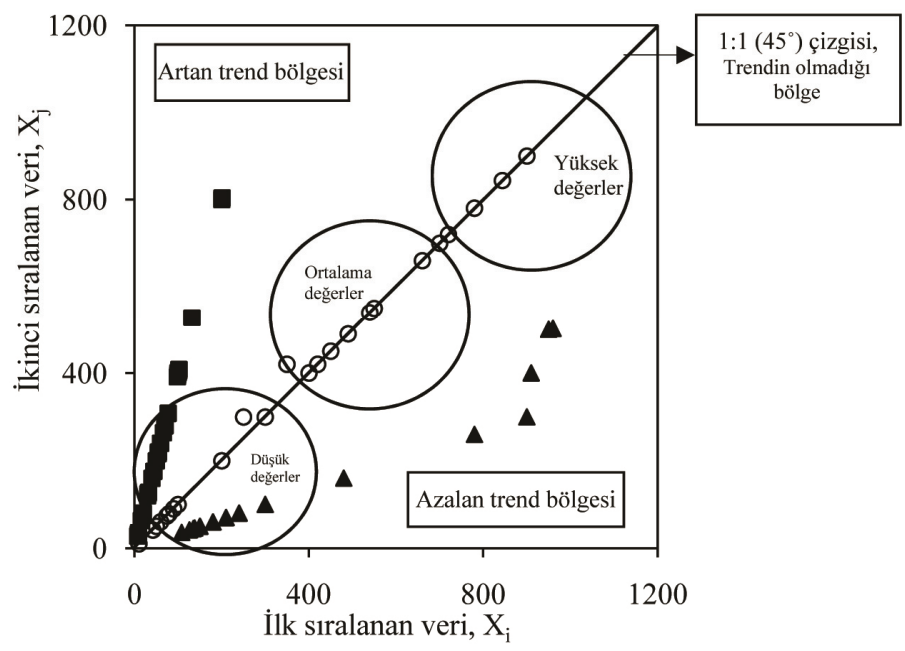

Şekil 2. Verilerin Kartezyen koordinatları üzerinde gösterilmesi, (Şen, 2012) 
Şen (2015) [17] çalışmasında metodu ilk metoda ek olarak matematik işlemlerin sonucunda tek yönlü hipotez testi ile sonuçların istatistiksel olarak anlamlılığını kontrol etmiştir. MK'den farklı olarak tek yönlü hipotez testini kullanılmakta ve çözümün aşamaları aşağıda özetlenmektedir.

$$
\begin{aligned}
& E(s)=\frac{2}{n}\left[E\left(\overline{\left.y_{2}\right)}-E\left(\overline{y_{1}}\right)\right]\right. \\
& \sigma_{s}^{2}=\frac{4}{n^{2}}\left[E\left({\overline{y_{2}}}^{2}\right)-2 E\left(\overline{y_{2} y_{1}}\right)-E\left({\overline{y_{1}}}^{2}\right)\right] \\
& \rho_{\overline{y_{2} y_{1}}}=\frac{E\left(\overline{y_{2} \overline{y_{1}}}\right)-E\left(\overline{y_{2}}\right)-E\left(\overline{y_{1}}\right)}{\sigma_{\overline{y_{2}}} \sigma_{\overline{y_{1}}}} \\
& \sigma_{s}^{2}=\frac{8}{n^{2}} \frac{\sigma^{2}}{n}\left(1-\rho_{\overline{y_{2}} \overline{y_{1}}}\right) \\
& \sigma_{s}=\frac{2 \sqrt{2}}{n \sqrt{n}} \sigma \sqrt{\left(1-\rho_{\overline{y_{2}}}\right)} \\
& K L_{(1-\alpha)}=0 \mp s_{k r i t i k} \sigma_{s}
\end{aligned}
$$

Burada, $\overline{y_{1}}$ : ilk serinin ortalamas1, $\overline{y_{2}}$ : ikinci serinin ortalamas1, $\rho$ : ilk ve ikinci serinin korelasyon katsayısı, s: eğim değeri, n: veri sayısı, $\sigma$ : tüm verinin standart sapması, $\sigma_{s}$ : eğim standart sapma değeri ve $s_{\text {kritik }}$ değeri ise ( $\% 95$ veya $\% 99$ gibi) güven aralıklarına karşılık gelen Z kritik değerlerini ifade etmektedir. Burada hesaplanan $\sigma_{s}$ değeri çok önemli olup, bu parametre ile Denklem 6'da hesaplanan kritik alt ve üst limit değerler trendin olup olmadığı için kurulan hipotez testi için sınır değerleri oluşturmaktadır. Denklem 1 ile hesaplanan s değeri, alt ve üst kritik limit değerlerinin arasında değil ise karşı hipotez olarak kurulan $\mathrm{H}_{1}$ hipotezi kabul edilmektedir [17]. Ĕgim değerinin (s) pozitif olması incelenen seride artan negatif olması da azalan bir trendi ifade etmektedir. Bu yöntem, Şen (2015) [17] çalışmasında, sıcaklık, akım ve yağış değişkenleri üzerinde uygulamıştır. İlk çalışmalarında ise, Şen (2013b) [16] tarafından Merkez/Bursa (yıllık ve aylık toplam yağış, $\mathrm{mm}$ ), Uludağ/Bursa (yıllık ve aylık toplam yağış, mm), Euphates Nehri (yıllık akım, $\mathrm{m}^{3} / \mathrm{sn}$ ) ve Danube Nehri'nin (yıllık akım, $\mathrm{m}^{3} / \mathrm{sn}$ ) uzun zaman ölçülmüş değişkenleri üzerinde uygulanmıştır. Ayrıca, bir başka çalışmasında, Şen (2012) [14] Aslantaş Barajı (yıllık akım, $\mathrm{hm}^{3}$ ), Menzelet Barajı (yıllık toplam akım, $\mathrm{hm}^{3}$ ), Cizre İstasyonu (yıllık toplam yağış, mm) ve Danube Nehri $\left(\mathrm{akım}, \mathrm{m}^{3} / \mathrm{sn}\right)$ verilerine uygulamıştır. Diğer bir çalışmada ise bu metot Şen (2013a) [15] tarafından Göztepe, Florya, Edirne, Bolu ve Bursa istasyonlarında uzun zaman ölçülmüşs sıcaklık değişkeni verilerine uygulanmıştır.

\subsection{Mann-Kendall (MK) trend belirleme yöntemi}

$\mathrm{Bu}$ yöntem, ölçümü alınan bir değişkenin zaman serisinin trend gösterip göstermediğini belirlemek için özellikle iklimbilim (klimatoloji) ve su bilimleri (hidroloji) problemlerinde sıklıkla kullanılan bir yöntemdir [26-28]. İlk olarak, ölçüm tarihinden bitiş tarihine $i=1, \ldots, n$-l'e kadar $x_{i}$ veri sütun serisi ile $j=i+1, \ldots, n$ 'e kadar sıralanmış olan bir $X_{j}$ veri 
sütunu ayarlanır. Daha sonra, $x_{i}$ veri sütunu başlangıç olarak kullanılır ve diğer sıralanmış $x_{j}$ ile Denklem 7'deki signum fonksiyonu kullanılarak Denklem 8'deki MK test istatistiği toplam $(S)$ değeri hesaplanır. Bu denklem, tüm veri çiftlerinin farkı $\left(x_{j}-x_{i}\right)$ sonucu oluşan pozitif ve negatif değerlerin sayısının toplamını ifade etmektedir.

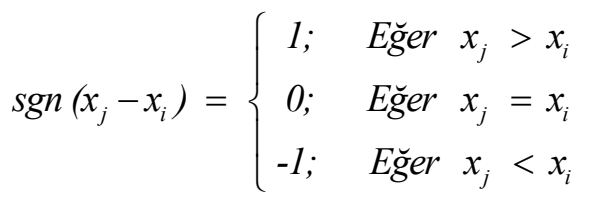

$$
\begin{aligned}
& S=\sum_{i=1}^{n-1} \sum_{j=i+1}^{n} \operatorname{sgn}\left(x_{j}-x_{i}\right)
\end{aligned}
$$

Denklem 9'da, $n$ : veri serisi uzunluğu, $P$ : serideki bağlı grupların sayıları, $t_{i}$ değeri ise $i$ uzunluğundaki bir seride bağlı gözlemlerin sayısıdır. Denklemdeki, toplama terimi, seride bağlı gözlem olduğunda kullanılır. Yani, bağlı gözlemler yoksa toplama terimi kullanılmaz.

$$
\operatorname{Var}(S)=\frac{n(n-1)(2 n+5)-\sum_{i=1}^{P} t_{i}\left(t_{i}-1\right)\left(2 t_{i}+5\right)}{18}
$$

Veri uzunluğu, $n>10$ olduğu seriler için Denklem 9'daki varyans hesabı yapılır ve burada verilerin yaklaşık olarak normal dağılıma (Standart sapma $(\sigma)=1$ ve ortalama $(\bar{X})=0$ ) uyduğu öngörülmektedir. Denklem 9 ile varyans hesaplandıktan sonra, Denklem 10'da, MK test istatistiğinin $(S)$ sınırlarına göre $Z$ değeri hesaplanmaktadır. Hesaplanan $Z$ değeri de, belirlenen çift yönlü güven $(\alpha=0.01$ veya $\alpha=0.05)$ düzeylerine karşıllı gelen normal dağılım tablosundaki standart $Z$ değerleriyle karşılaştırılmaktadır.

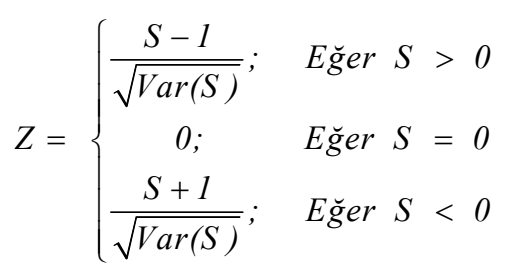

Testlerin anlamlılık düzeyleri genellikle normal dağılım için çoğu mühendislik uygulamalarında sıklıkla kullanılan $0.10(\alpha=\% 10)$ ve $0.05(\alpha=\% 5)$ olasılığına sahip çift yönlü güven aralıkları öngörülmektedir. Hesap sonucu, elde edilen $Z$ istatistiği değeri, $\alpha$ anlamlılık düzeyine karş̧ gelen normal dağılımın $Z_{1-\alpha / 2}$ değerinden büyük olduğu zaman trendin olmadığ trendin olduğu şeklinde kurulan $\mathrm{H}_{1}$ hipotezi kabul edilmektedir. Denklem 8 ile hesaplanan $\mathrm{S}$ test istatistiğinin değeri pozitif ise, incelenen olayda artan yönde, negatif ise azalan yönde bir trend olduğu sonucuna varılmaktadır [26-28]. 


\section{UYGULAMA}

MK ve Şen trend yöntemlerinin sonuçları, 1517 (Karanlık Dere, Şefaatli), 1524 (Gökırmak, Kuyluş), 1528 (Kızılırmak Nehri, Salur Köprüsü) ve 1539 (Kızılırmak Nehri, Bulakbaşı) nolu AGI'lere uygulanması sonuçları elde edilen çizelge ve grafikler yorumlanmıştır. Her bir istasyona ait verilerin zaman aralıkları ve MK testi yönteminin sonuçları Çizelge 1'de verilmiştir. Çizelge 1'e göre, 1524 ve 1539 kodlu istasyonlarda hesaplanan $Z$ değerleri, $\alpha=0.10$ ve $\alpha=0.05$ çift yönlü güven aralığına karşılık gelen $Z$ değerlerinden küçük olduğu için $\mathrm{H}_{0}$ hipotezi kabul edilmekte olup bu istasyonlarda ölçülen akım değişkeninde bir trendin olmadığ 1 sonucuna varılmaktadır. 1517 ve 1528 kodlu istasyonlar için hesaplanan $\mathrm{Z}$ değeri, kritik $\mathrm{Z}$ değerlerinden mutlak değerce büyük olduğundan bu istasyonlardaki akım değişkeni istatistiksel olarak da $\% 95$ güven aralığında anlamlı ve azalan bir trendin olduğu bulunmuştur. Diğer bir ifade ile $\mathrm{H}_{0}$ hipotezinin reddedilmesi anlamına geldiği ve akım değişkeninin azalan yönde bir trendin olduğunu ifade edebiliriz.

Çizelge 2. Aylık olarak ölçülmüş akım değişkeni için Mann-Kendall (MK) test sonuçları

\begin{tabular}{|c|c|c|c|c|c|c|}
\hline $\begin{array}{c}\text { İstasyon } \\
\text { numarası }\end{array}$ & $\begin{array}{c}\text { Veri aralığı, } \\
\text { Yıl }\end{array}$ & $\begin{array}{c}\text { Test } \\
\text { istatistiği } \\
\text { (S) }\end{array}$ & $\begin{array}{c}\text { Hesaplanan } \\
\pm \mathbf{Z} \text { değeri }\end{array}$ & $\begin{array}{c}\text { Z, Kritik } \\
\text { olasılık } \\
\text { değeri, } \\
\mathbf{\alpha}=\mathbf{0 . 0 5}\end{array}$ & $\begin{array}{c}\text { Trend } \\
\text { (+ veya -) }\end{array}$ & $\begin{array}{c}\mathbf{H}_{\mathbf{0}} \\
\text { Hipotezi }\end{array}$ \\
\hline 1517 & $1994-2010$ & -5497 & $-5.32^{*}$ & \pm 1.96 & Var (-) & Red \\
\hline 1524 & $1991-1998$ & 32 & 0.09 & \pm 1.96 & Yok & Kabul \\
\hline 1528 & $1991-1997$ & -446 & $-1.99^{*}$ & \pm 1.96 & Var (-) & Red \\
\hline 1539 & $1991-1994$ & 78 & 0.89 & \pm 1.96 & Yok & Kabul \\
\hline
\end{tabular}

Uygulanan Şen (2015) trend testi sonuçları Şekil 3, 4, 5 ve 6'da ve analiz özeti ise Çizelge 3'de yer almaktadır. Şekil 3'te 1517 nolu istasyonun gidiş ve saçılma grafiklerine göre verilerin çoğunun 1:1 çizgisinin altında kaldığı açıkça görülmektedir. Gidiş grafiğine göre ise azalan bir lineer trendin olduğu görülmektedir. Dolayısıyla ilk bakışta azalan bir trendin olduğu söylenebilir. Ancak sorunun cevabı, yapılan matematik işlem ve istatistik analiz adımlarına göre Çizelge 3'de yer almaktadır. Çizelgedeki hesaplanan s değeri \%95 güven düzeyindeki kritik değerlerin dışında olduğu için istatistiksel olarak \%95 güven düzeyinde anlamlı ve azalan bir trendin olduğu ve sonucun MK testi ile benzer olduğu görülmektedir.

1524 nolu istasyon için Şekil 4'de gidiş ve saçılma grafiklerinde, 1:1 çizgisine göre aylık akım değişkeninin yüksek ve ortalama değerleri için azalan bir trendin olduğu söylenebilir. Çizelge 3'e bakıldığında ise s değeri \%95 güven düzeyinde hesaplanan kritik değerlerin dışında olduğu için bu sonucun istatistiksel olarak $\% 95$ güven düzeyinde anlamlı ve azalan bir trendin olduğu görülmektedir. Bu sonuç MK testinden farklı olduğu görülmektedir.

1528 nolu istasyonunun saçılma ve gidiş grafikleri Şekil 5'de verilmiştir. Şekillere göre, 1528 kodlu istasyondaki ölçümlerin tümü $1: 1$ çizgisinin altındaki alanda toplandığı ve azalan bir trendin olduğu açıkça görülmektedir. Çizelge 3'e bakıldığında ise, yine 
hesaplanan s değeri $\% 95$ güven düzeyinde hesaplanan kritik değerlerin dışında olduğu için bu sonucun istatistiksel olarak \%95 güven düzeyinde anlamlı ve azalan bir trendin olduğu görülmektedir. Bu sonuç, MK testi ile benzer olduğu görülmektedir.

Şekil 6'da, 1539 kodlu istasyona bakıldığında ise verilerin dağınık olduğu görülmektedir. Ancak Çizelge 3'ye bakıldığında hesaplanan s değeri \%95 güven düzeyinde hesaplanan kritik değerlerin içinde olduğu için istatistiksel olarak anlamlı bir trendin olmadığ görülebilir. Bu sonucun $\mathrm{MK}$ testi ile benzerliği görülmektedir.
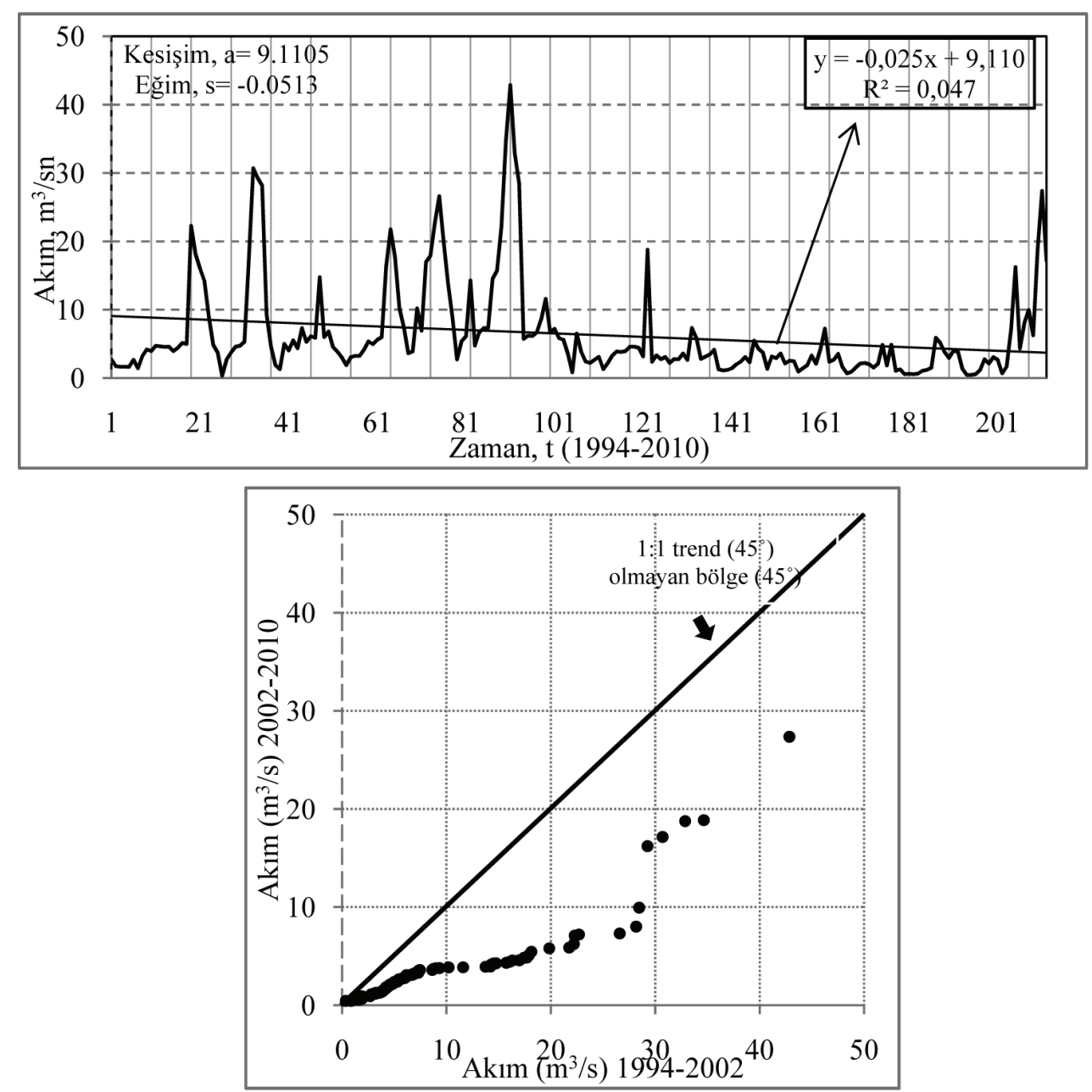

Şekil 3. 1517-Karanlık Dere, Şefaatli (1994-2010) nolu istasyona ait Şen (2015) metodu sonuçları 
Murat AY, Özgür Kișị
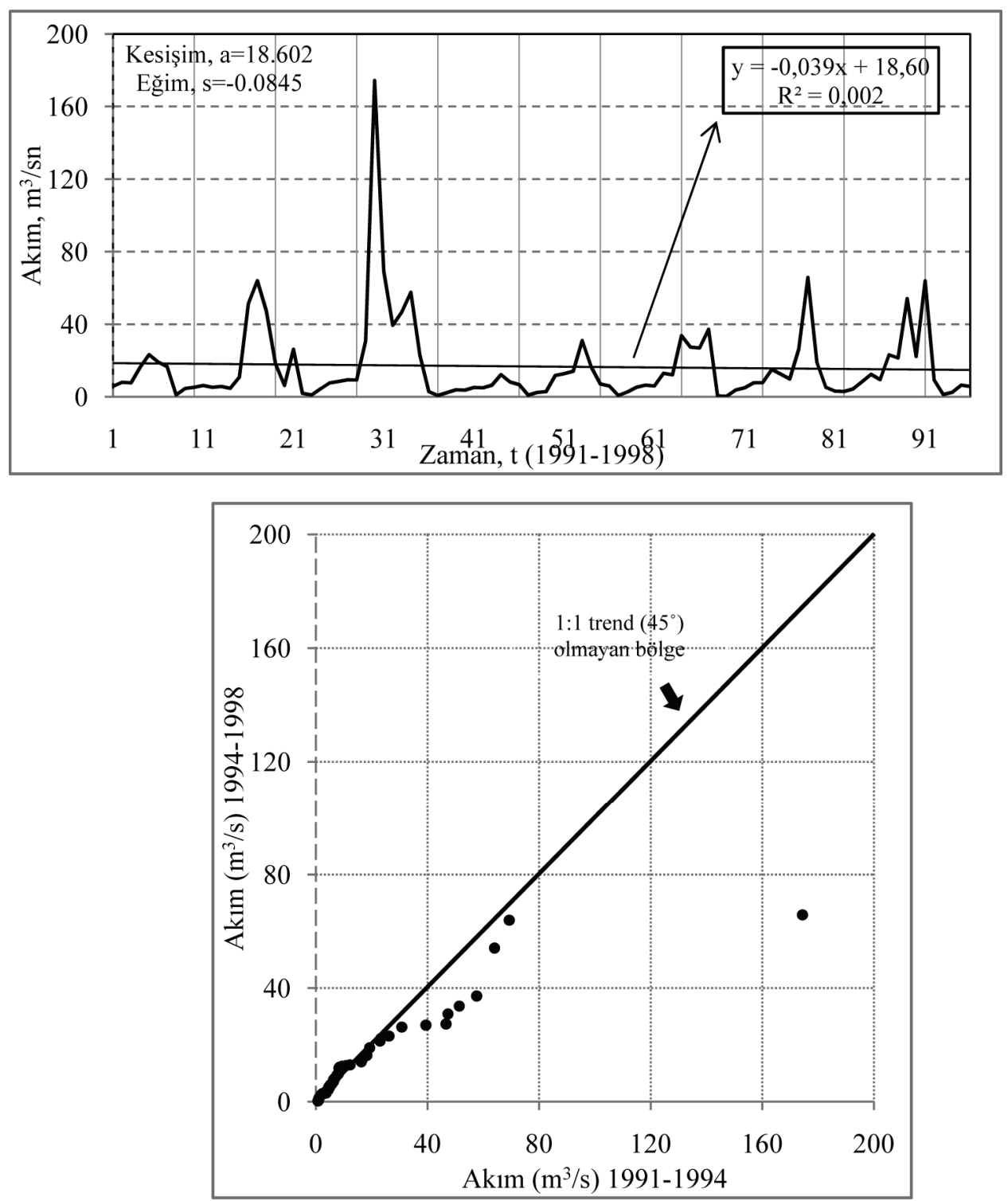

Şekil 4. 1524- Göktrmak, Kuyluş (1991-1998) nolu istasyona ait Şen (2015) metodu sonuçları 
Kızllırmak Nehrinde Bazı İstasyonlardaki Akımların Trend Analizi
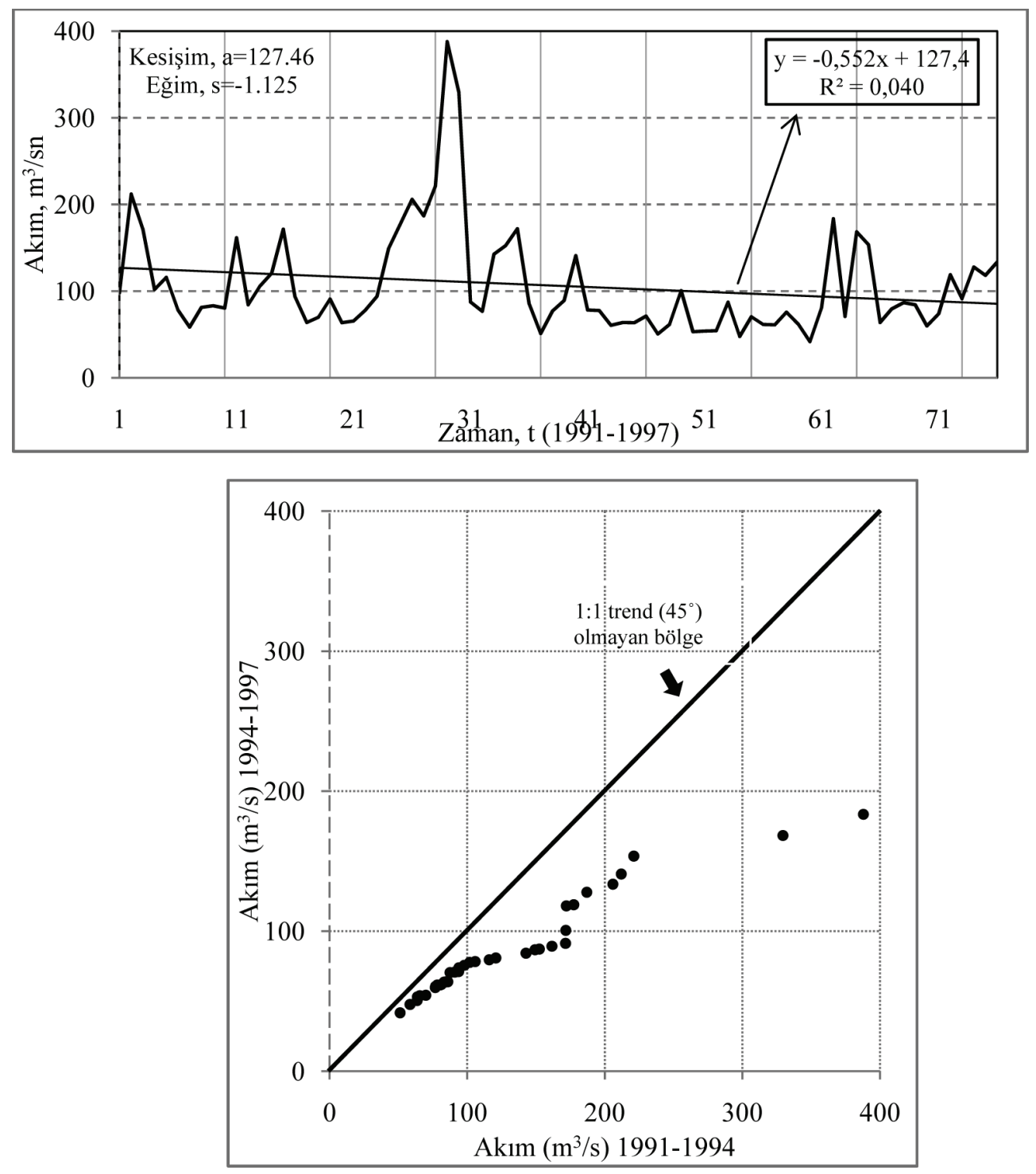

Şekil 5. 1528-Kızllırmak Nehri, Salur köprüsü (1991-1997) nolu istasyona ait Şen (2015) metodu sonuçları 

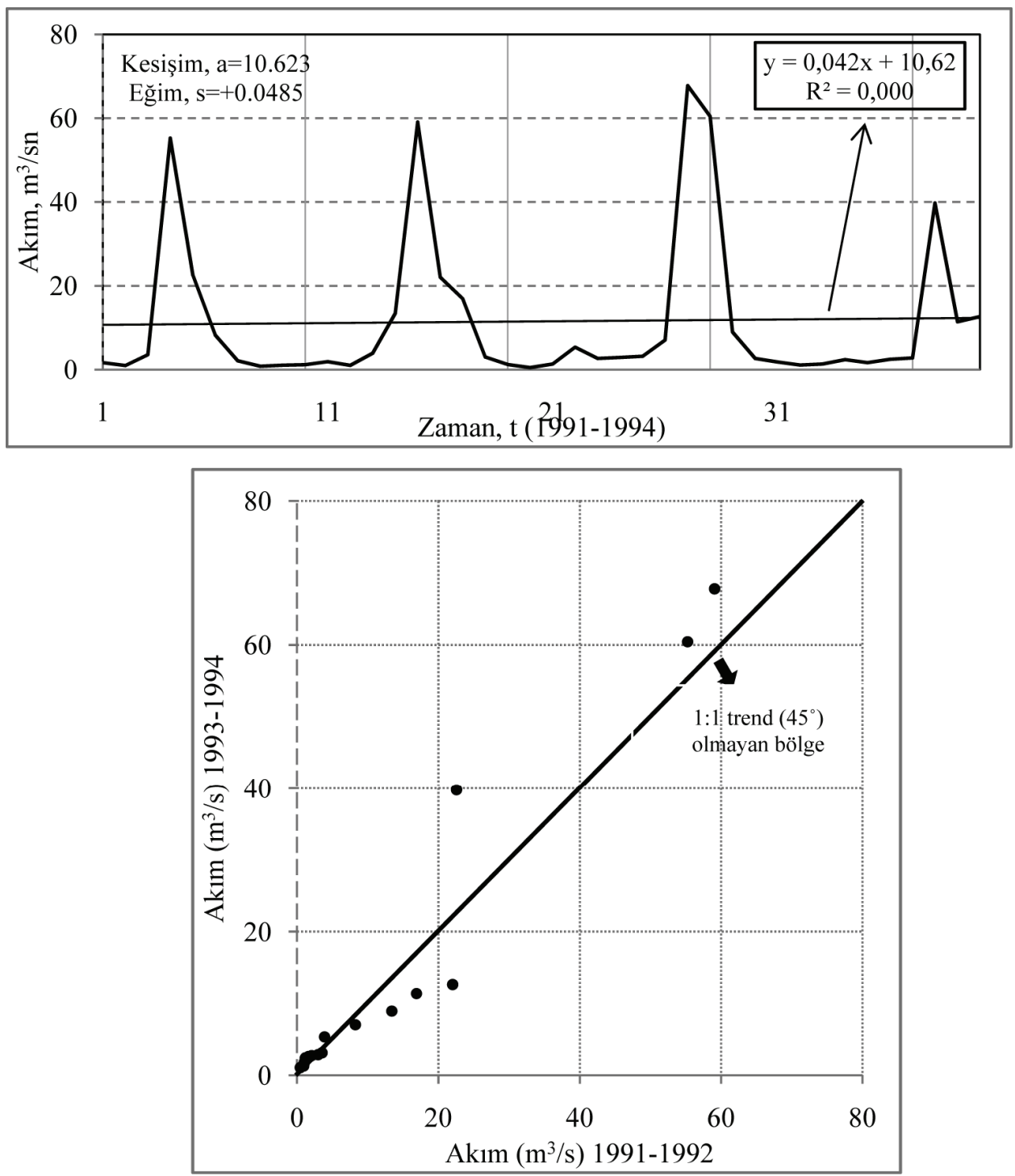

Şekil 6. 1539-Kızılırmak Nehri, Bulakbaşı (1991-1994) nolu istasyona ait Şen (2015) metodu sonuçları

İstasyonların gidiş grafiklerindeki verilere bakıldığında, doğadaki aktiviteleri, akarsu kesitlerindeki değişimler, akarsu boyunca gölet/baraj yapımı, içme, sulama, kullanma veya başka amaçlar için akarsudan alınan sular veya hatalı ölçümler, istasyon yerlerinin değişimi, yeraltı su seviyelerinin değişimleri gibi etkiler bu istasyonlarda da söz konusu olabilir. Bu bakımdan, ana kütleden alınan örneklemin homojenliği bozulabilmektedir. Devlet Su İşleri’nden alınan bilgilere göre, 1524 istasyon 1999 yılında 1528 nolu istasyon 
ise 1997 yılında kapatılmıştır. Bu istasyonlardan alınan veriler bölgede yapılacak olan su yapıları için kullanılmıştır. 1517 nolu istasyon ise Yozgat ilinde ve Gelingüllü barajının mansap tarafında olan Şefaatli ilçesi sınırlarındadır. Gelingüllü barajı 1994 yılında bitmiş olup su tutmaya başlamış̧ır. Bu tarihten sonra yani baraj yapıldıktan sonra ölçülen veriler çalışmada kullanılmıştır. Diğer taraftan göze çarpan bir diğer husus olarak; uç (ekstrem) verilerin istasyonlardaki trend sonuçlarına etkisine bakıldığında çalışmanın diğer bölümlerinde de yer alan bilgilere ek olarak örneğin doğrusal trendlere bakıldığında söz konusu istasyonlar için Şen metoduyla kıyaslandığında benzer sonuçların elde edildiği görülmüştür.

Çizelge 3. Şen (2015) trend test sonuçları

\begin{tabular}{|c|c|c|c|c|c|}
\hline No & \multirow[b]{2}{*}{$\begin{array}{l}\text { İstasyon adı ve } \\
\text { numarası }\end{array}$} & \multirow{2}{*}{$\begin{array}{l}\text { Karanlık } \\
\text { Dere, Şefaatli } \\
-1517\end{array}$} & \multirow{2}{*}{$\begin{array}{l}\text { Gökırmak, } \\
\text { Kuyluş } \\
-1524\end{array}$} & \multirow{2}{*}{$\begin{array}{c}\text { Kizılırmak } \\
\text { Nehri, Salur } \\
\text { Köprüsü } \\
-1528\end{array}$} & \multirow{2}{*}{$\begin{array}{l}\text { Kızılırmak } \\
\text { Nehri, } \\
\text { Bulakbaşı } \\
-1539\end{array}$} \\
\hline 1 & & & & & \\
\hline 2 & Veri tipi & $\operatorname{Akım}\left(\mathrm{m}^{3} / \mathrm{sn}\right)$ & $\operatorname{Akım}\left(\mathrm{m}^{3} / \mathrm{sn}\right)$ & $\operatorname{Akım}\left(\mathrm{m}^{3} / \mathrm{sn}\right)$ & $\operatorname{Akım}\left(\mathrm{m}^{3} / \mathrm{sn}\right)$ \\
\hline 3 & Veri sayısı, n & 212 & 96 & 76 & 40 \\
\hline 4 & Eğim, s (+ ya da -) & -0.0513 & -0.0845 & -1.125 & +0.0485 \\
\hline 5 & Kesişim, a & 9.11 & 18.60 & 127.46 & 10.62 \\
\hline 6 & Standart sapma, $\sigma_{\mathrm{n}}$ & 7.16 & 23.18 & 60.8 & 18.39 \\
\hline 7 & Ortalama, $(\bar{X})$ & 6.39 & 16.67 & 106.21 & 11.49 \\
\hline 8 & $\begin{array}{l}\text { Korelasyon } \\
\text { katsay1s1 (r), } \rho_{\text {ylort., }} \\
\text { y2ort., }-1 \leq r \leq+1\end{array}$ & 0.9103 & 0.9061 & 0.9657 & 0.9686 \\
\hline 9 & $\begin{array}{l}\text { Eğim standart } \\
\text { sapmas1, } \sigma_{\mathrm{s}}\end{array}$ & 0.001964 & 0.023159 & 0.04807 & 0.03643 \\
\hline 10 & $\begin{array}{l}\text { Anlamlıl11k düzeyi, } \\
\alpha=0.05 \text { (Tek yönlü) }\end{array}$ & 0.05 & 0.05 & 0.05 & 0.05 \\
\hline 11 & $\begin{array}{l}\text { Üst sınır (güven } \\
\text { düzeyi, \%95) }\end{array}$ & +0.00324 & +0.03808 & +0.07907 & +0.0599 \\
\hline 12 & $\begin{array}{l}\text { Alt sınır (güven } \\
\text { düzeyi, \%95) }\end{array}$ & -0.00324 & -0.03808 & -0.07907 & -0.0599 \\
\hline 13 & $\begin{array}{l}\text { Hipotezler } \\
\left(\mathrm{H}_{0} \text { ya da } \mathrm{H}_{1}\right) \\
\end{array}$ & $\mathrm{H}_{1}$ & $\mathrm{H}_{1}$ & $\mathrm{H}_{1}$ & $\mathrm{H}_{0}$ \\
\hline 14 & $\begin{array}{l}\text { Karar } \\
\text { (Evet ya da Hayır) }\end{array}$ & Evet & Evet & Evet & Hayır \\
\hline 15 & $\begin{array}{l}\text { Trend tipi (artan, } \\
\text { azalan veya trend } \\
\text { yok) }\end{array}$ & Azalan & Azalan & Azalan & Trend yok \\
\hline
\end{tabular}


Murat AY, Özgür Kiş̧̇

\section{SONUÇLAR VE ÖNERILER}

Yarı-kurak iklim kuşağında olan Türkiye'nin Kızılırmak Havzası'ndan seçilen 4 farklı AGI'de aylık olarak ölçülen akım verileri kullanılarak hem Mann (1945)-Kendall (1975) hem de yeni önerilen Şen (2012) yöntemleri ile trend analizleri araştırılmış ve uygulanan iki yöntemin karşılaştırmaları yapılmıştır. Çalışma sonuçları kapsamında, genel olarak, istasyonların koordinatlarına göre akım trendlerinin değişken olduğu söylenebilir. Bu değişkenliğin sebepleri olarak, bölgedeki yerleșim, nüfus, sanayi ve tarım arazileri alanları, yağış miktarları, yükselti değerleri ve hava durumlarından kaynaklı farklılıklar sayılabilir. Bu sonuçların, yağış ve sıcaklık değişsenleriyle doğrudan bağlantılı olduğu ve diğer çalışmalardaki sonuçlar ile değişkenlik gösterme noktasında paralel olduğu yani bölgeden bölgeye hatta istasyondan istasyona farklılıkların var olduğu ifade edilebilir.

Mann-Kendall yöntemine göre, 1524 ve 1539 nolu istasyonlarında kayda değer bir trend bulunmamıştır. 1517 ve 1528 nolu istasyonlarda $\% 95$ güven düzeyinde istatistiksel olarak anlamlı azalan bir trend bulunmuştur. Bu sonuçlardan hareketle, yeni önerilen Şen yönteminin çıktılarına bakıldığında, 1517, 1524 ve 1528 nolu istasyonlarda istatistiksel olarak \%95 güven düzeyinde anlamlı ve azalan bir trendin olduğu görülmüştür. 1539 nolu istasyonda ise herhangi bir trend bulunmamıştır. Görüldüğü üzere, MK'dan farklı olarak sadece 1524 nolu istasyon farklı sonuçlar vermiştir.

Çalışmada incelenen Şen yönteminin Mann-Kendall'a göre birçok üstünlüğü görülmektedir. Bunlardan biri, Şen yöntemi hiçbir kabule dayanmamakta ve daha az veri ile de analiz yapılabilmektedir. İkinci üstünlüğü ise trendin grafik olarak değerlendirilmesi ve düşük, orta ve yüksek değerlerdeki tüm aralıklarında trendlerin gözlenebilmesidir. Bu sayede de genel olarak yüksek akımların olduğu Mart ve Nisan ayları ile düşük akımların olduğu Temmuz ve Ağustos aylarında, akarsudaki akımın nasıl bir trend olduğu yaklaşık olarak yorumlanabilir. Ayrıca, uygulanan trend belirleme yöntemleri incelenen bölgelerin akım değişkeni için bir bakıș açısı geliştirmede yardımcı olduğu söylenebilir. Günümüz koşulları ve küresel iklim değişikliği olgusunun daha iyi analiz edilebilmesi için tüm bölgelerde ölçüm alınan istasyon sayılarının arttırılması, bu gibi yöntemlerin daha güvenilir sonuç vermesi açısından gerekli olup tasarlanan mühendislik yapılarının da fonksiyonelliğinin bir göstergesi olarak değerlendirilebilir.

Netice itibariyle, hidrometrik, hidrolojik, meteorolojik ve diğer su çevrimi ilgili ölçümler için istasyon sayılarının artırılması ve kaliteli ekipmana sahip istasyonların kurulması, anlık ölçümlerin, gerçek zamanlı ölçümlerin olması, herhangi bir olumsuz bir duruma karşı hızlı önlem almada kullanılabilir. Ayrıca bu sistemler, havza bilgi sistemlerinin oluşturulmasında çok önemli bir yere sahip oldukları için yapılacak olan mühendislik uygulamalarının da alt yapısını oluşturmaktadır.

\section{Semboller}

a : Kesişim

AGİ : Akım gözlem istasyonu

$\mathrm{H}_{0} \quad$ : Hipotezde öne sürülen bir önerinin savunulması

$\mathrm{H}_{1} \quad$ : Hipotezde öne sürülen bir önerinin karşıt durumda olması 


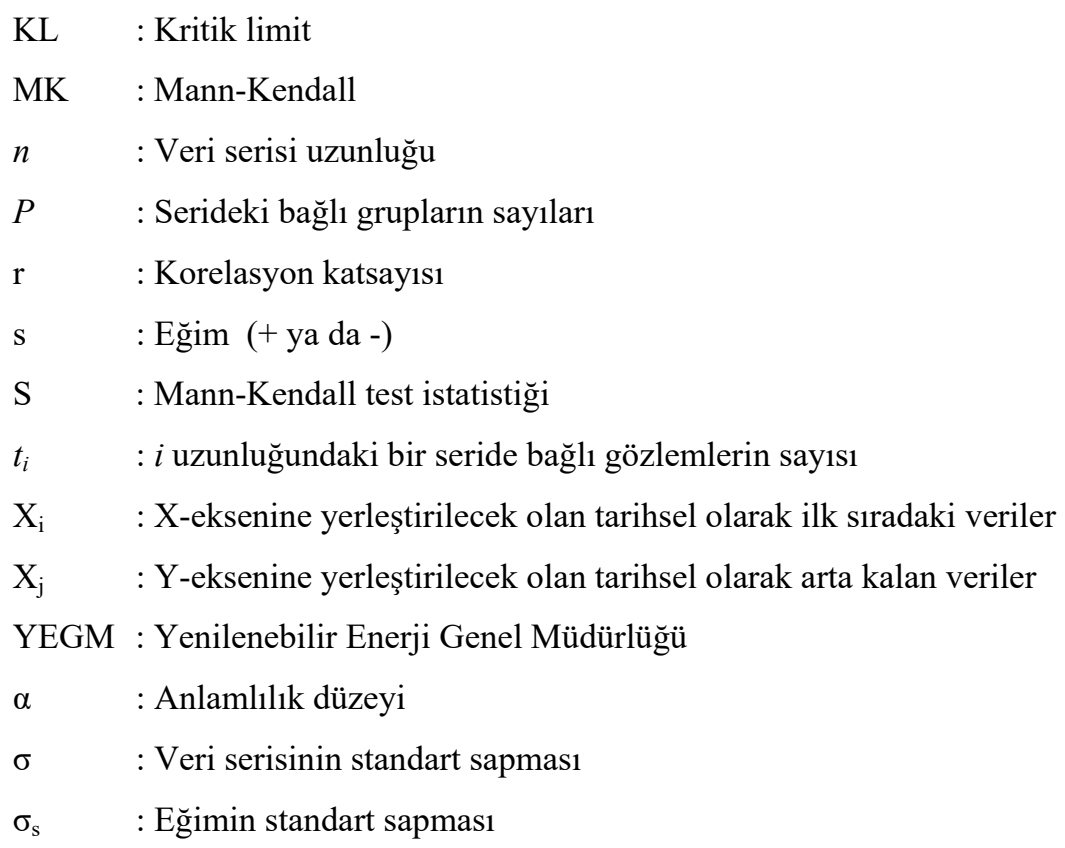

\section{Teşekkür}

Yazarlar, bu çalışmada kullanılan verileri sağlayan Yenilenebilir Enerji Genel Müdürlüğü'nün saha çalışmalarındaki personellerine, ofis çalışanlarına ve çalışmayı titizlikle inceleyen çok değerli hakemlere içtenlikle teşekkür ederler.

\section{Kaynaklar}

[1] Reddy, V.R., Syme, G.J., Social sciences and hydrology: An introduction, Journal of Hydrology, 518, Part A, 1-4, 2014.

[2] Yevjevich, V., Stochastic processes in hydrology, Water Resources Publications, 276p. Fort Collins, CO., 1972.

[3] Kottegoda, N.T., Stochastic water resources technology, The MacMillan Press, 1980.

[4] Turkes, M., Spatial and Temporal Analysis of Annual Rainfall Variations in Turkey, International Journal of Climatology, 16, 1057-1076, 1996.

[5] Mortsch, L., Hengeveld, H., Lister, M., Lofgren, B., Quinn, F., Slivitzky, M. and Wenger, L., Climate change impacts on the hydrology of the Great Lakes-St. Lawrence system, Canadian Water Resources Journal, 25(2), 153-179, 2000.

[6] IPCC, Climate change 2007: Climate change impacts, adaptation and vulnerability. Working Group II contribution to the Intergovernmental Panel on Climate Change Fourth Assessment Report. Summary for Policymakers, 23, 2007. 
[7] Lettenmaier, D.P., Wood, E.F. and Wallis, J.R., Hydroclimatological trends in the continental United States, 1948-1988, Journal of Climate, 7(4), 586-607, 1994.

[8] Whitfield, P. H. and Cannon, A. J., Recent variations in climate and hydrology in Canada, Canadian Water Resources Journal, 25(1), 19-65, 2000.

[9] Cigizoglu, H. K., Bayazit, M. and Onoz, B., Trends in the maximum, mean and low flows of Turkish rivers, Journal of Hydrometeorology, 6(3), 280-290, 2005.

[10] Marengo, J.A., Interdecadal variability and trends of rainfall across the Amazon basin, Theoretical and Applied Climatology, 78, 79-96, 2004.

[11] Zhang, X., Harvey, K. D., Hogg W. D. and Yuzyk, T. R., Trends in Canadian streamflow, Water Resources Research, 37(4), 987-998, 2001.

[12] Novotny, E.V. and Stefan, H.G., Streamflow in Minnesota: Indicator of climate change, Journal of Hydrology, 334, 319-333, 2007.

[13] Haktanir, T., Bajabaa, S. and Masoud, M., Stochastic analyses of maximum daily rainfall series recorded at two stations across the Mediterranean Sea, Arabian Journal of Geosciences. DOI: 10.1007/s12517-012-0652-0, 2012.

[14] Şen, Z., Innovative trend analysis methodology, Journal of Hydrologic Engineering, 17(9), 1042-1046, 2012.

[15] Şen, Z., Trend Identification Simulation and Application, ASCE, Journal of Hydrologic Engineering. doi: 10.1061/(ASCE)HE.1943-5584.0000811, 2013.

[16] Şen, Z., Square Diagonal Trend Test Procedure. $6^{\text {th }}$ International Perspective on Water Resources \& The Environment. January, 07-09, Konferansta sunulan tam bildiri kompakt diskte yer almaktadır. İzmir, Turkey, 2013.

[17] Şen, Z. Innovative trend significance test and applications, Theoretical and Applied Climatology, DOI 10.1007/s00704-015-1681-x, 2015.

[18] Duhan, D. and Pandey, A., Statistical analysis of long term spatial and temporal trends of precipitation during 1901-2002 at Madhya Pradesh, India, Atmospheric Research, 122, 136-149, 2013.

[19] Kisi, O. and Ay, M., Comparison of Mann Kendall and innovative trend method for water quality parameters of the Kizilirmak River, Turkey, Journal of Hydrology, 513, 362-375, 2014.

[20] Kadığlu, M., Trends In Surface Air Temperature Data Over Turkey. International Journal of Climatology, 15, 511-520, 1997.

[21] Burn, D.H. and Elnur, M.A.H., Detection of hydrologic trends and variability, Journal of Hydrology, 255, 107-122, 2002.

[22] Kahya, E. and Kalayci, S., Trend analysis of streamflow in Turkey, Journal of Hydrology, 289(1-4), 128-144, 2004.

[23] Van Belle, G. and Hughes, J.P., Nonparametric tests for trend in water quality, Water Resources Research, 20(1), 127-136, 1984. 
Kızllırmak Nehrinde Bazı İstasyonlardaki Akımların Trend Analizi

[24] Birsan, M. V., Molnarp, P., Burlandop, P. and Pfaundlerm, M., Streamflow trends in Switzerland, Journal of Hydrology, 314 (1-4), 312-329, 2005.

[25] Gocic, M. and Trajkovic, S., Analysis of changes in meteorological variables using Mann-Kendall and Sen's slope estimator statistical tests in Serbia, Global and Planetary Change, 100, 172-182, 2013.

[26] Helsel, D.R. and Hirsch, R.M., Statistical Methods in Water Resources. Techniques of Water-Resources Investigations of the United States Geological Survey Book 4, Chapter A3, Hydrologic Analysis, and Interpretation, 2002.

[27] Kendall, M. G., Rank correlation methods, Oxford University Press, New York, 1975.

[28] Mann, H. B., Nonparametric tests against trend, Econometrica, 13(3), 245-259, 1945. 